Article

\title{
Investigation of the Electrochemical Breakdown Response in Sensitised AA5083 Aluminium Alloy
}

\author{
YanHan Liew ${ }^{1,2,3} \mathbb{D}^{\text {, }}$, Sudesh Wijesinghe ${ }^{2,3}$ and Daniel J. Blackwood ${ }^{3, *} \mathbb{D}$ \\ 1 Integrative Sciences and Engineering Programme, NUS Graduate School, National University of Singapore, \\ Singapore 119077, Singapore; YHLIEW@nus.edu.sg \\ 2 Reliability and Characterisation Unit, Singapore Institute of Manufacturing Technology (SIMTech), \\ Agency for Science, Technology and Research (A*STAR), Singapore 138634, Singapore; \\ sudeshw@simtech.a-star.edu.sg \\ 3 Department of Materials Science and Engineering, National University of Singapore, \\ Singapore 117575, Singapore \\ * Correspondence: msedjb@nus.edu.sg
}

Citation: Liew, Y.; Wijesinghe, S.; Blackwood, D.J. Investigation of the Electrochemical Breakdown Response in Sensitised AA5083 Aluminium Alloy. Sustainability 2021, 13, 7342 https://doi.org/10.3390/su13137342

Academic Editors: Ime Bassey Obot, Ambrish Singh, Akram Alfantazi and Ihsan ulhaq Toor

Received: 13 May 2021

Accepted: 28 June 2021

Published: 30 June 2021

Publisher's Note: MDPI stays neutral with regard to jurisdictional claims in published maps and institutional affiliations.

Copyright: (c) 2021 by the authors. Licensee MDPI, Basel, Switzerland This article is an open access article distributed under the terms and conditions of the Creative Commons Attribution (CC BY) license (https:// creativecommons.org/licenses/by/ $4.0 /)$.

\begin{abstract}
The light-weight aluminium alloys play an important role in reducing emissions from the transport industry. However, to take full advantage of these, the corrosion mechanisms that govern their failure need to be properly understood. Hence, the electrochemical response, especially after passive film breakdown, of the aluminium alloy AA5083 was analysed via potentiodynamic polarisation. By starting the scans at the relatively negative potential of $-1.4 \mathrm{~V}$ (vs. SCE), the reduction of water in the electrolyte causes a localised increase in $\mathrm{pH}$, leading to a preferential attack on the susceptible regions in the (sensitised) microstructure; that is, the deleterious $\beta-\mathrm{Al}_{3} \mathrm{Mg}_{2}$ along the grain boundaries. Subsequently, in the later stages of the potentiodynamic scan, these regions that have been degraded by the dissolution of $\beta-\mathrm{Al}_{3} \mathrm{Mg}_{2}$ undergo imperfect repassivation, leading them to be vulnerable to localised breakdowns. These conditions allowed for the discovery of a discernible trend after breakdown, in which AA5083 microstructures with a more extensive $\beta-\mathrm{Al}_{3} \mathrm{Mg}_{2}$ region (both in size and in amount) recorded a more rapid increase in the measured current density. In particular, the potential at which the anodic current density reached $1 \times 10^{-4} \mathrm{~A} \mathrm{~cm}^{-2}$ was correlated with the extent of $\beta-\mathrm{Al}_{3} \mathrm{Mg}_{2}$ formed during isothermal heat-treatments. This work provides a possible pathway towards the development of an electrochemical quantification technique for the extent of $\beta-\mathrm{Al}_{3} \mathrm{Mg}_{2}$ growth, degree of sensitisation, and, ultimately, the intergranular corrosion (IGC) susceptibility of the microstructure of AA5083 components used in industrial applications.
\end{abstract}

Keywords: aluminium alloy 5083; sensitisation; potentiodynamic polarisation; $\beta-\mathrm{Al}_{3} \mathrm{Mg}_{2}$

\section{Introduction}

An important method of energy saving, and thus sustainability, is the utilisation of lightweight components; for example, aluminium alloys have a high strength-to-weight ratio. Nevertheless, the manufacture of aluminium is energy intensive, such that the embodied energy of its alloys is high, so that it is vital that once formed these materials should not be lost back to their ores via corrosion. In this respect, grade 5083 AluminiumMagnesium alloy (AA5083) is an important grade of industrial alloy used mainly in the marine and transportation industries, for applications such as ship manufacturing and pressure vessels, due to its superior general/uniform corrosion resistance [1]. However, the non-homogenous microstructure of AA5083, involving the presence of various intermetallic particles (IMPs), will lead to regions that are susceptible to localised corrosion attacks during service [1-3].

Importantly, when exposed to elevated temperatures of around $50-200{ }^{\circ} \mathrm{C}$, the solubility of $\mathrm{Mg}$ in the Al-Mg solid solution (of the AA5083) increases, such that on cooling back to ambient temperatures it will be in a supersaturated condition, leading to the preferential 
precipitation of the deleterious $\beta-\mathrm{Al}_{3} \mathrm{Mg}_{2}$ phase along the grain boundaries [4-7]. It is well-known that extensive $\beta-\mathrm{Al}_{3} \mathrm{Mg}_{2}$ along the grain boundaries can lead to intergranular corrosion (IGC) [4] and intergranular stress corrosion cracking (IGSCC) [8,9]; $\beta-\mathrm{Al}_{3} \mathrm{Mg}_{2}$ is reported to be electrochemically active in the AA5083 microstructure as it has a corrosion potential approximately $200-500 \mathrm{mV}$ more negative than that of AA5083 [3,10]. However, at the higher open circuit potential of AA5083, the dissolution of the active $\beta-\mathrm{Al}_{3} \mathrm{Mg}_{2}$ phase has not been properly characterised in terms of how this leads to IGC initiation or propagation; some authors have postulated this to be due to re-dissolution of surface $\beta-\mathrm{Al}_{3} \mathrm{Mg}_{2}$ during sample preparation [11].

Overall, the behaviour of $\beta-\mathrm{Al}_{3} \mathrm{Mg}_{2}$ during the potential window from when it loses passivity until the actual (higher) breakdown potential of the AA5083 microstructure has not been properly investigated, with IGC spreading (both on the surface and into the matrix) also having been suggested to occur within this potential range $[9,12,13]$. Furthermore, it is intuitive and well-reported that the breakdown potential of AA5083 decreases with a more sensitised microstructure (the microstructure is considered to be sensitised when there is extensive $\beta-\mathrm{Al}_{3} \mathrm{Mg}_{2}$ along the grain boundaries) $[4,12,14]$. However, due to the metastable nature of pits in aluminium alloys [15], the region around the breakdown produces noisy electrochemical readings; it is difficult to definitively characterise the breakdown. Without proper understanding of the corrosion mechanisms involved and the behaviour of the nm-scaled $\beta-\mathrm{Al}_{3} \mathrm{Mg}_{2}$ in the AA5083 microstructure, the establishment and formation of a clear and quantitative electrochemical framework to characterise IGC susceptibility in the 5XXX grade aluminium alloys is hindered.

Recently, Trueba and Trasatti [16] explored the repassivation response of the AA5083 microstructure after electrochemical breakdown, and concluded that there is a distinct difference in behaviour of the sensitised and non-sensitised microstructure. Comparably, in our work, the electrochemical response just after breakdown was investigated; this occurs after the electrochemical conditioning of the microstructure, postulated to have affected its passivation response. Significantly, this work revealed an observable trend correlated to the extent of precipitation of the deleterious $\beta-\mathrm{Al}_{3} \mathrm{Mg}_{2}$ in the AA5083 microstructure. This provides a possible pathway towards the long-term aim of benchmarking and on-site electrochemical quantitative characterisation of IGC susceptibility in 5XXX aluminium alloys that is safer, faster, and more precise, as compared to the traditional Nitric Acid Mass Loss Test (NAMLT) [17].

\section{Materials and Methods}

Commercial AA5083-H2 (UNS A95083) sheet (1.2 mm thick) samples were investigated; the sheet was cut into dimensions of around $15 \mathrm{~mm} \times 15 \mathrm{~mm}$. The nominal chemical composition of the main alloying elements for the AA5083 microstructure is shown in Table 1, as characterised via X-ray fluorescence spectroscopy (XRF). The general microstructure of AA5083 employed in this study is comprised of the $\mu \mathrm{m}$-sized aluminide and silicide IMPs, as well as the submicron-sized $\beta-\mathrm{Al}_{3} \mathrm{Mg}_{2}$; scanning electron microscopy (SEM) characterisation with energy-dispersive $\mathrm{X}$-ray spectroscopy (EDX) analysis of the general microstructure and larger IMPs of a heavily sensitised $\left(160{ }^{\circ} \mathrm{C}\right.$ for 30 days) AA5083 sample has been previously reported in our earlier work [18].

Table 1. Chemical composition (wt.\%) of the AA5083-H2 samples investigated.

\begin{tabular}{cccccccc}
\hline Al & Mg & Mn & Cr & Fe & Si & Cu & Zn \\
\hline $94.607 \pm 0.439$ & $3.909 \pm 0.451$ & $0.661 \pm 0.051$ & $0.079 \pm 0.030$ & $0.424 \pm 0.034$ & $0.147 \pm 0.039$ & $0.032 \pm 0.006$ & $0.021 \pm 0.004$ \\
\hline
\end{tabular}

To prepare varying degrees of sensitisation (DoS) in the AA5083 microstructure, the samples were subjected to isothermal heat treatments; the conditions were chosen based on recommendations from the other literature $[7,11,19]$. The first step was a solutionising heat treatment at $450{ }^{\circ} \mathrm{C}$ for $6 \mathrm{~h}$ to prepare an AA5083 microstructure essentially free of 
$\beta-\mathrm{Al}_{3} \mathrm{Mg}_{2}$ precipitation, thus providing a common starting point for the thermo-processing history independent of the original manufacturing conditions. This was followed by sensitisation heat treatments at $175{ }^{\circ} \mathrm{C}$, varying from two days $(48 \mathrm{~h})$ to three months (2160 h). In addition, tests were also conducted on as-received microstructures/samples, which did not undergo any of the aforementioned isothermal heat treatments. Table 2 illustrates the variation of the eight sample types investigated in this work and their corresponding isothermal heat treatments.

Table 2. Isothermal heat treatments performed on the AA5083 specimens along with the approximate fraction of $\beta-\mathrm{Al}_{3} \mathrm{Mg}_{2}$ (and dispersoids) in the different types.

\begin{tabular}{ccc}
\hline $\begin{array}{c}\text { Isothermal Heat Treatment } \\
\text { History }\end{array}$ & Duration (Hours) & $\begin{array}{c}\text { Approximate Fraction of } \boldsymbol{\beta}-\mathbf{A l}_{3} \mathbf{M g}_{2} \\
\text { (and Dispersoid) (\%) }\end{array}$ \\
\hline Solutionised $\left(450^{\circ} \mathrm{C}\right)$ & 6 & $0.4 \pm 0.1$ \\
\hline & 48 & $2.0 \pm 1.5$ \\
Solutionised $\left(450^{\circ} \mathrm{C}, 6 \mathrm{~h}\right)$, & 336 & $3.4 \pm 0.5$ \\
then Sensitised $\left(175^{\circ} \mathrm{C}\right)$ & 720 & $3.4 \pm 0.3$ \\
& 1440 & $6.3 \pm 0.5$ \\
& 2160 & $10.4 \pm 0.3$ \\
As-Received & - & $1.8 \pm 0.1$ \\
\hline
\end{tabular}

Prior to the electrochemical experiments, the AA5083 samples were mechanically ground down to 4000-grit with $\mathrm{SiC}$ sandpaper, followed by polishing down to $1 \mu \mathrm{m}$ mirror finish with diamond paste, and then a $0.05 \mu \mathrm{m}$ finish with colloidal silica suspension (OP-S non dry, Struers, Copenhagen, Denmark). From our experience, the finish with colloidal silica suspension was able to reveal the $\beta-\mathrm{Al}_{3} \mathrm{Mg}_{2}$ phase on the surface, which was depicted by Seong et al. [11] to be protected by an altered surface layer during sample preparation. Minimal exposure to water, especially during the polishing steps, was required as there are intermetallic particles (IMPs) ( $\beta-\mathrm{Al}_{3} \mathrm{Mg}_{2}$ and $\mathrm{Mg}_{2} \mathrm{Si}$ ) in the AA5083 microstructure that are known to be electrochemically active when exposed to an electrolyte [3,20].

The electrochemical tests were conducted with a Gamry (Philadelphia, PA, USA) Interface 1000 potentiostat and an Avesta three-electrode cell (Singapore), with a graphite rod counter electrode and a saturated calomel reference electrode (SCE); the electrochemical potential readings in this work are reported to be versus SCE. The electrolyte involved in the test was deaerated $3.5 \mathrm{wt} . \% \mathrm{NaCl}$ solution at room temperature; a $1 \mathrm{~cm}^{2}$ area of the sample was exposed to the electrolyte. Deaeration was achieved by a $1 \mathrm{~h}$ bubbling of nitrogen gas into the electrolyte prior to the electrochemical test; to reduce regress of oxygen into the cell during the experiments, nitrogen gas was also lightly bubbled at the top of the solution during the electrochemical tests.

In general, the electrochemical experiments began with a $1 \mathrm{~h}$ open circuit potential (OCP) monitoring, to ensure that the sample surfaces were at a relatively stable condition. Then, unless otherwise specified, full potentiodynamic polarisation scans were conducted at $0.1667 \mathrm{mV} \mathrm{s}^{-1}$, starting from $-1.40 \mathrm{~V}$ (vs. SCE) until the anodic current density exceed $1 \mathrm{~mA} \mathrm{~cm}^{-2}$, which occurred after breakdown of the passive film. In order to ensure reproducibility, a minimum of three separate scans/tests were conducted on separate freshly polished samples for each type of specimen (varied by duration of sensitisation heat treatment). The electrochemical readings/data were analysed using the Gamry (Philadelphia, PA, USA) Echem Analyst software v6.25 and OriginPro software.

For visualisation of the local microstructure, an Olympus (Tokyo, Japan) MX51 optical microscope $(\mathrm{OM})$ was utilised. When required, the microstructure was etched with $10 \mathrm{wt} . \%$ ammonium persulfate (AP) solution to assist in visualising the nm-scaled $\beta-\mathrm{Al}_{3} \mathrm{Mg}_{2}$ [21]. A semi-quantitative approximation of the etched area was derived using the "Olympus Stream" image analysis software for phase analysis. For the calculation of the approximate fraction of $\beta-\mathrm{Al}_{3} \mathrm{Mg}_{2}$ (and dispersoids) in each type of microstructure, a minimum of 
three random locations from three separate samples of the same heat-treatment type were considered. However, etching can also occur in regions where (vulnerable) dispersoids are present, therefore there is a need to correct for this by etching the solutionized samples. If one assumes that the solutionized samples contain no $\beta-\mathrm{Al}_{3} \mathrm{Mg}_{2}$ then the extent of etching in these samples comes solely from the (vulnerable) dispersoids, allowing us to correct the $\beta-\mathrm{Al}_{3} \mathrm{Mg}_{2}$ fractions for the sensitized samples. In practice, as shown in Table 2, the correction required was less than $20 \%$.

\section{Results}

\subsection{Microstructural Analysis-Degree of Sensitisation}

Here, the focus of the investigation is on the response from microstructures with a varying degree of sensitization; therefore, on the varying degree of precipitation of the smaller nm-sized to sub-micron range $\beta-\mathrm{Al}_{3} \mathrm{Mg}_{2}$ phase. Figure 1 illustrates a sensitised (175 ${ }^{\circ} \mathrm{C}$ for two months) microstructure, before and after slight etching in $10 \mathrm{wt} . \% \mathrm{AP}$; the presence of the slight etching along the grain boundaries is evidence of $\beta-\mathrm{Al}_{3} \mathrm{Mg}_{2}$ precipitation [21].

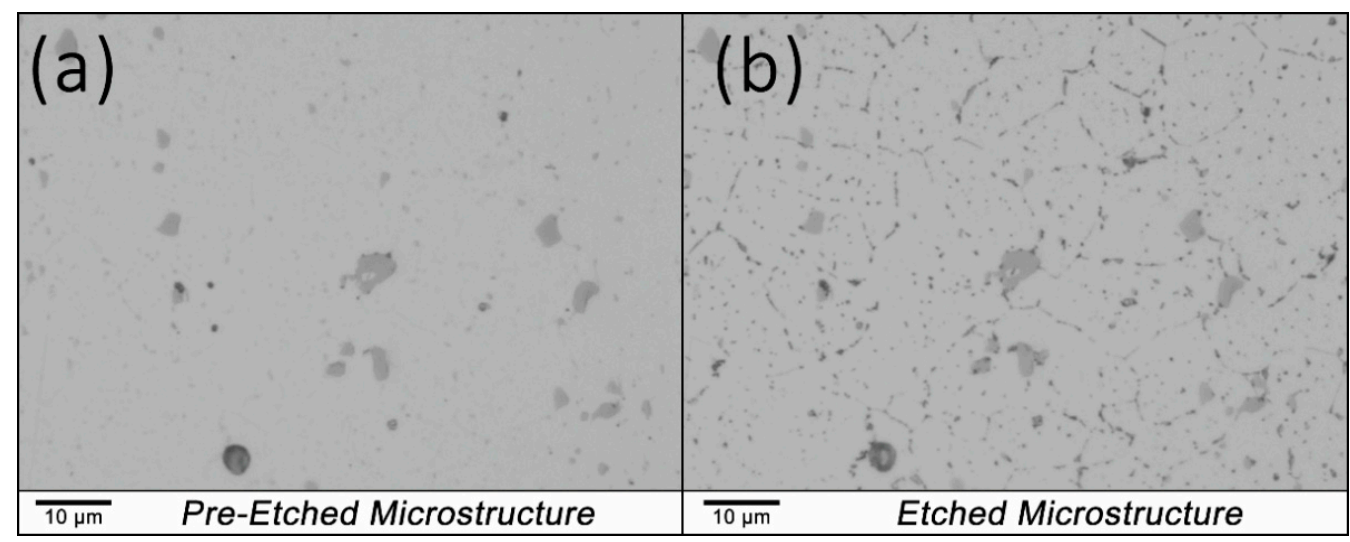

Figure 1. Optical microscopy (OM) analysis of the AA5083 sensitised ( $175{ }^{\circ} \mathrm{C}$ for two months) microstructure, (a) freshly polished before etching and (b) after etching in $10 \mathrm{wt} . \%$ ammonium persulfate (AP) solution for $1 \mathrm{~min}$.

Furthermore, with the assistance of the etchant, Figure 2 compares the difference in DoS of a solutionised microstructure and a heavily sensitised microstructure. The grain boundaries (and matrix) of the solutionised microstructure are not etched (Figure 2a), indicating that there is minimal precipitation of the deleterious $\beta-\mathrm{Al}_{3} \mathrm{Mg}_{2}$ in its microstructure. It should be noted at this point that the sensitised microstructures were prepared from a previously solutionised microstructure; the solutionised microstructure serves as a starting point for minimal DoS (and $\beta-\mathrm{Al}_{3} \mathrm{Mg}_{2}$ precipitation) in the AA5083 microstructure.

Overall, as expected, there was a general increase in the amount of the microstructure etched with an increased duration of isothermal sensitisation heat treatment at $175{ }^{\circ} \mathrm{C}$ [7]; EDX analysis also revealed enrichment of $\mathrm{Mg}$ along the grain boundaries of the sensitised microstructure (Figure S1), indicating the presence of $\beta-\mathrm{Al}_{3} \mathrm{Mg}_{2}$. Table 2 provides a semiquantitative approximation of the area etched in the microstructure by using the "Olympus Stream" image analysis software for phase analysis.

While the contributions from the larger $\mu \mathrm{m}$-sized aluminides and silicides were removed from the approximated fraction of $\beta-\mathrm{Al}_{3} \mathrm{Mg}_{2}$, any dispersoids within the microstructure could not be disregarded as these are not easily differentiated from the $\beta-\mathrm{Al}_{3} \mathrm{Mg}_{2}$ phase; the term dispersoids is used here to refer to other (i.e., not $\left.\beta-\mathrm{Al}_{3} \mathrm{Mg}_{2}\right) \mathrm{nm}$-sized or sub-micron phases that are also vulnerable to being revealed by the etching process. Nevertheless, the approximate fraction of $\beta-\mathrm{Al}_{3} \mathrm{Mg}_{2}$, plus dispersoids derived for the solutionised microstructure $(0.4 \pm 0.1 \%$; Table 2$)$, can be considered to represent the maximum amount of non- $\beta-\mathrm{Al}_{3} \mathrm{Mg}_{2}$ dispersoids; the solutionised microstructure is believed to contain min- 
imal $\beta-\mathrm{Al}_{3} \mathrm{Mg}_{2}$ precipitation and the dispersoids are likely to undergo Oswald ripening in subsequent heat-treatments, reducing their contribution to the calculated fraction of $\beta-\mathrm{Al}_{3} \mathrm{Mg}_{2}$ plus dispersoids. Therefore, because the approximate fraction of $\beta-\mathrm{Al}_{3} \mathrm{Mg}_{2}$ plus dispersoids derived for the other (sensitised) microstructures (Table 2) are all much larger than $0.4 \%$ of the solutionised sample, it can be assumed that these values derive predominantly from $\beta-\mathrm{Al}_{3} \mathrm{Mg}_{2} ; \mathrm{SEM} / \mathrm{EDX}$ analysis was also employed to ascertain that the areas etched predominately coincide with the $\beta-\mathrm{Al}_{3} \mathrm{Mg}_{2}$ phase along the grain boundaries (Figure S1).

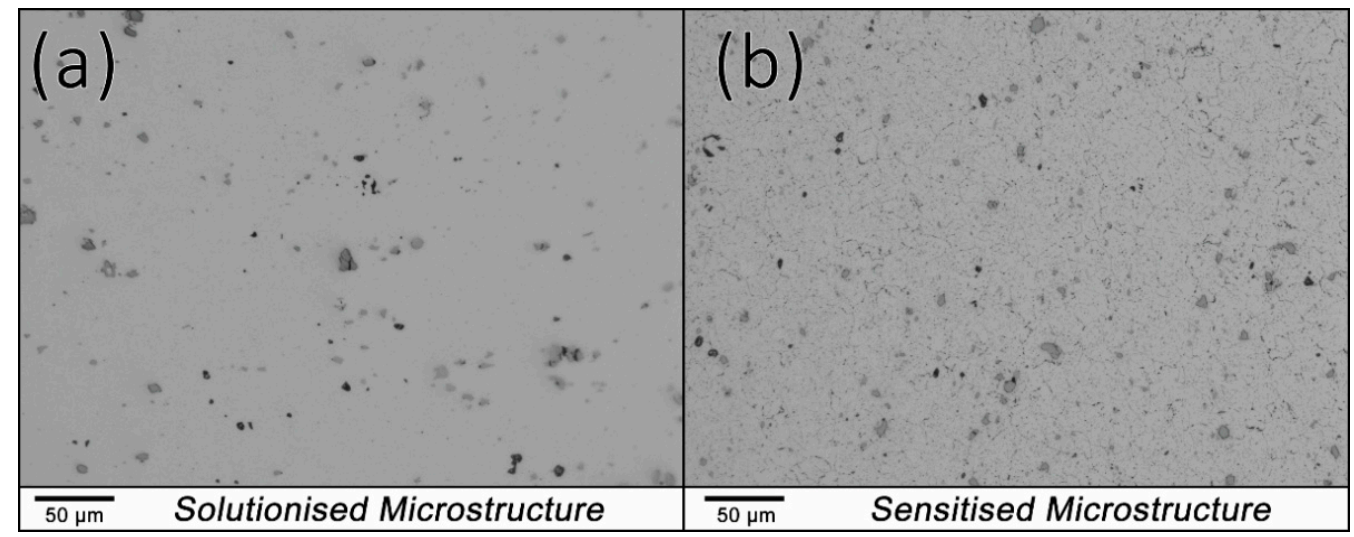

Figure 2. OM analysis after etching in $10 \mathrm{wt} . \% \mathrm{AP}$ solution for $1 \mathrm{~min}$ of the (a) solutionised $\left(450{ }^{\circ} \mathrm{C}\right.$ for $6 \mathrm{~h}$ ) microstructure and (b) heavily sensitised $\left(175^{\circ} \mathrm{C}\right.$ for three months) microstructure.

Lastly, it should be acknowledged that there may be some $\beta-\mathrm{Al}_{3} \mathrm{Mg}_{2}$ particles, whereby the etching of which might be too small to be observed under the optical microscope. However, these are likely to be of a smaller industrial concern than the (larger) $\beta-\mathrm{Al}_{3} \mathrm{Mg}_{2}$ particles that were etched and observed under optical microscopy; the propagation of localised corrosion depends on the acidification of the occluded electrolyte and that the extent of this acidification is a function of the size of cavity created by the dissolution of the $\beta-\mathrm{Al}_{3} \mathrm{Mg}_{2} \mathrm{IMPs}$. It should also be re-iterated that this is a semi-quantitative approximation used with the intention of a rapid screening test.

\subsection{Electrochemical Potentiodynamic Polarisation Scans}

Figure 3 shows the potentiodynamic polarisation scans obtained for the solutionised microstructure (Figure $3 \mathrm{a})$ and the heavily sensitised $\left(175^{\circ} \mathrm{C}\right.$ for three months) microstructure (Figure $3 b$ ); the scans of the other types of microstructures are available in the supplementary information section (Figure S2).

Localised breakdowns in AA5083, or aluminium alloys in general, have been reported to be related to micro-galvanic interactions between IMPs and their peripheral regions [2,22,23], or even within the IMPs themselves [24,25]. These breakdowns can produce a localised drop in $\mathrm{pH}$ in the vicinity of regions undergoing active dissolution, which can further autocatalyse the breakdown and/or trigger other breakdowns, such as the spreading of IGC; Jain et al. $[12,13]$ used a cooperative interactions model to demonstrate that, if precipitates $\left(\beta-\mathrm{Al}_{3} \mathrm{Mg}_{2}\right)$ are close enough in AA5083, pits can grow as a chain to form a network of corroded boundaries.

The main focus of this study is on the electrochemical response of the AA5083 (sensitised) microstructures after breakdown, and its correlation to the amount of $\beta-\mathrm{Al}_{3} \mathrm{Mg}_{2}$ in the microstructure. Hence, emphasis is placed onto the region of the polarisation curves from the breakdown potential to about $200 \mathrm{mV}$ beyond it; ca, $-0.8 \mathrm{~V}$ to $-0.5 \mathrm{~V}$ vs. SCE. Analysis of the post-experimental microstructures (Figure S3) indicates signs of localised corrosion attack in the sensitised microstructures, including intergranular corrosion along the grain boundaries and trenching around IMPs; trenching around noble (vs. matrix) 
micron-sized IMPs in aluminium alloys is well-illustrated in the literature, even for nonsensitised microstructures $[2,11,22]$.

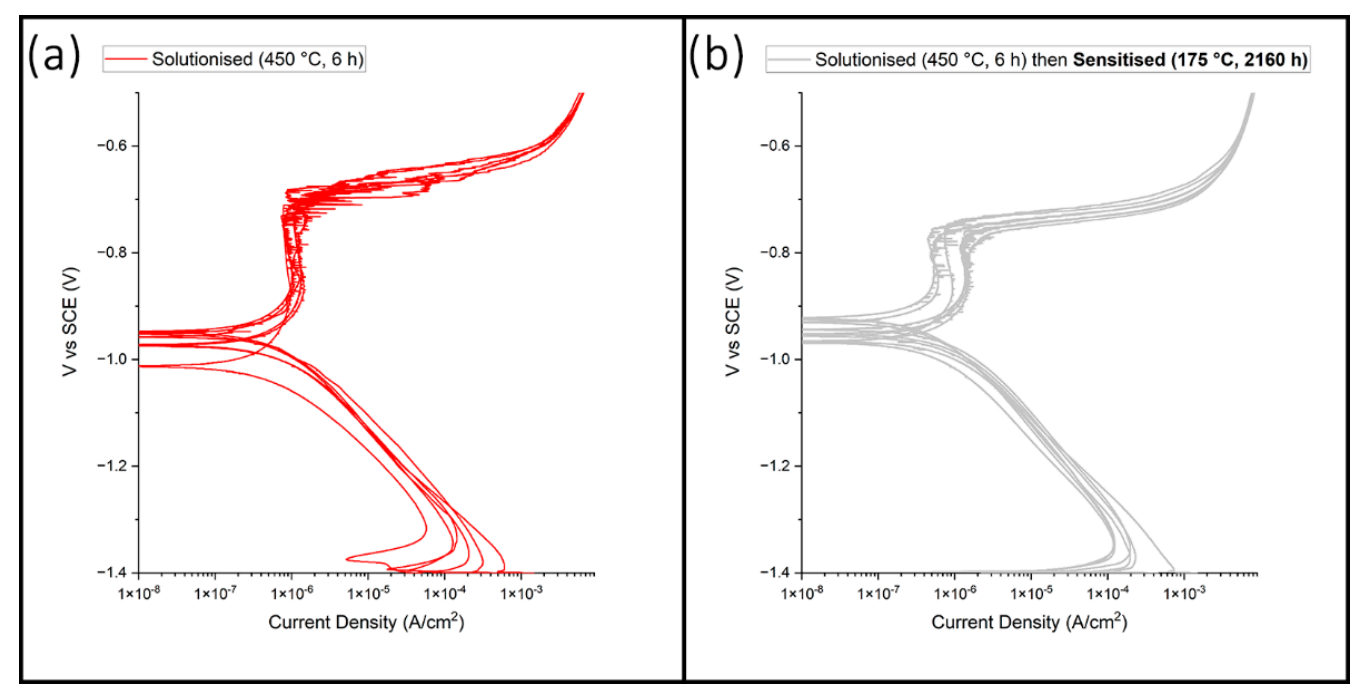

Figure 3. Potentiodynamic polarisation curves for the AA5083 (a) solutionised microstructure and the (b) heavily sensitised $\left(175^{\circ} \mathrm{C}\right.$ for three months) microstructure in deaerated $3.5 \mathrm{wt} . \% \mathrm{NaCl}$ electrolyte.

Figure 4 compares the aforementioned regions of the curves from the sensitised microstructures of varying isothermal heat treatment duration at $175^{\circ} \mathrm{C}$; three representative curves from each microstructure type are shown. It can be seen that the electrochemical measurements are relatively noisy close to the breakdown (Figure 4) due to the metastable nature of pits in aluminium alloys [15], making it hard to distinguish a clear breakdown potential, especially for those specimens that were only subjected to short heat-treatments. Nevertheless, a clear trend that can be seen between the microstructure types is breakdown occurring at more negative potentials as the heat-treatment time increased. It is intuitive that with an increased DoS, the breakdown of the microstructure will occur at a lower potential. However, the main focus of the classical literature has been on the noisier region of the breakdown potential itself; hence, clear trends have been difficult to discern at the breakdown potential itself $[11,12,16]$. In contrast, the focus on further breakdown propagation under the experimental settings employed in this work (full scan from $-1.4 \mathrm{~V}$ vs. SCE) has managed to produce a clear discernible trend (Figure 4).

\subsection{Microstructural Analysis—Electrochemical Potentiostatic Polarisation}

The experimental settings for the full electrochemical potentiodynamic polarisation scans from $-1.4 \mathrm{~V}$ (vs. SCE) assisted to produce the discernible trend in Figure 4. Next, potentiostatic polarisation scans together with microstructural analysis were conducted to obtain an idea of the qualitative differences in the microstructure that can arise depending on the starting potential of the full scan.

Figure 5 illustrates the microstructure of the heavily sensitised $\left(175{ }^{\circ} \mathrm{C}\right.$ for three months) microstructure, before and after a five minute potentiostatic hold at $-1.2 \mathrm{~V}$ (vs. SCE) and $-1.4 \mathrm{~V}$ (vs. SCE) in deaerated $3.5 \mathrm{wt} . \% \mathrm{NaCl}$; a one hour OCP was performed prior to the potentiostatic holds. The $\beta-\mathrm{Al}_{3} \mathrm{Mg}_{2}$ along the grain boundaries are visibly attacked (slightly) for the sensitised microstructure after the potentiostatic hold at $-1.4 \mathrm{~V}$ (vs. SCE) for five minutes (Figure 5d), whereas the potentiostatic hold at $-1.2 \mathrm{~V}$ (vs. SCE) (Figure $5 b$ ) did not appear to cause any preferential attack on the $\beta-\mathrm{Al}_{3} \mathrm{Mg}_{2}$ along the grain boundaries. Potentiostatic holds at $-1.6 \mathrm{~V}$ and $-2.0 \mathrm{~V}$ (vs. SCE) (Figure S4) indicated severe attacks along the grain boundaries, with even attack on the aluminides' peripheral region causing dropout of aluminides; undermining (Comparison of Figure S4c,d indicates 
darker contrasted regions in Figure S4d resembling "pits" due to the dropout of the initially-present aluminide in Figure S4c).

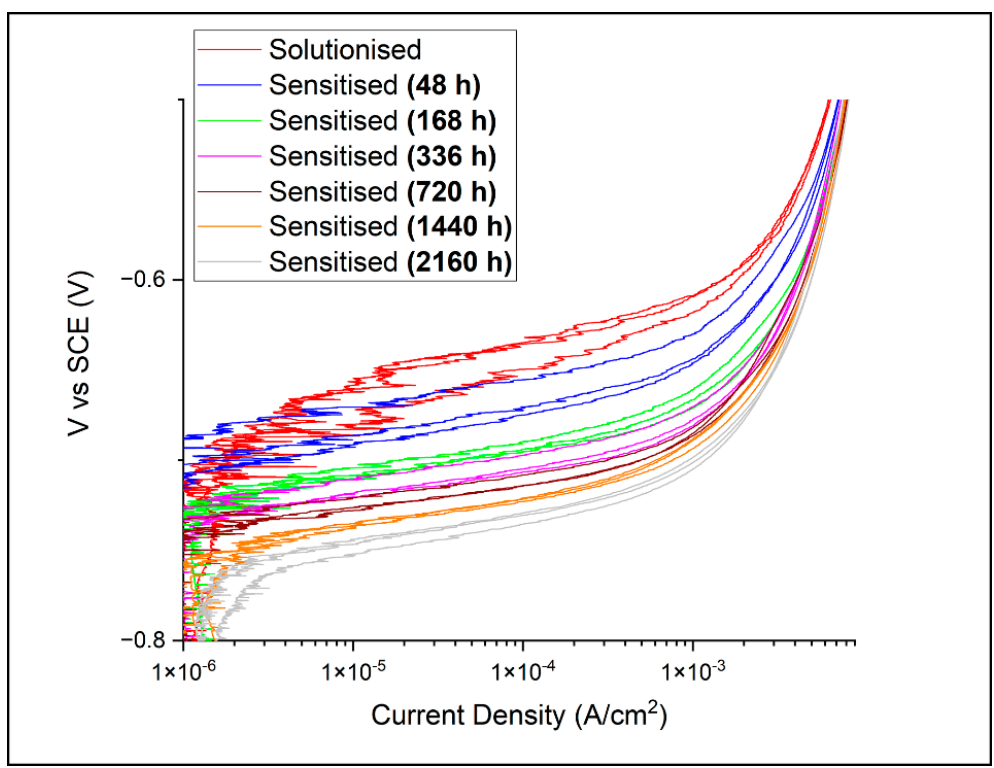

Figure 4. Comparison of the electrochemical potentiodynamic polarisation curves of the various AA5083 microstructures in the region near breakdown until when the anodic current density is over $1 \mathrm{~mA} \mathrm{~cm}^{-2}$. A discernible trend is obtained under the experimental settings employed in this work (full scan from $-1.4 \mathrm{~V}$ vs. SCE).

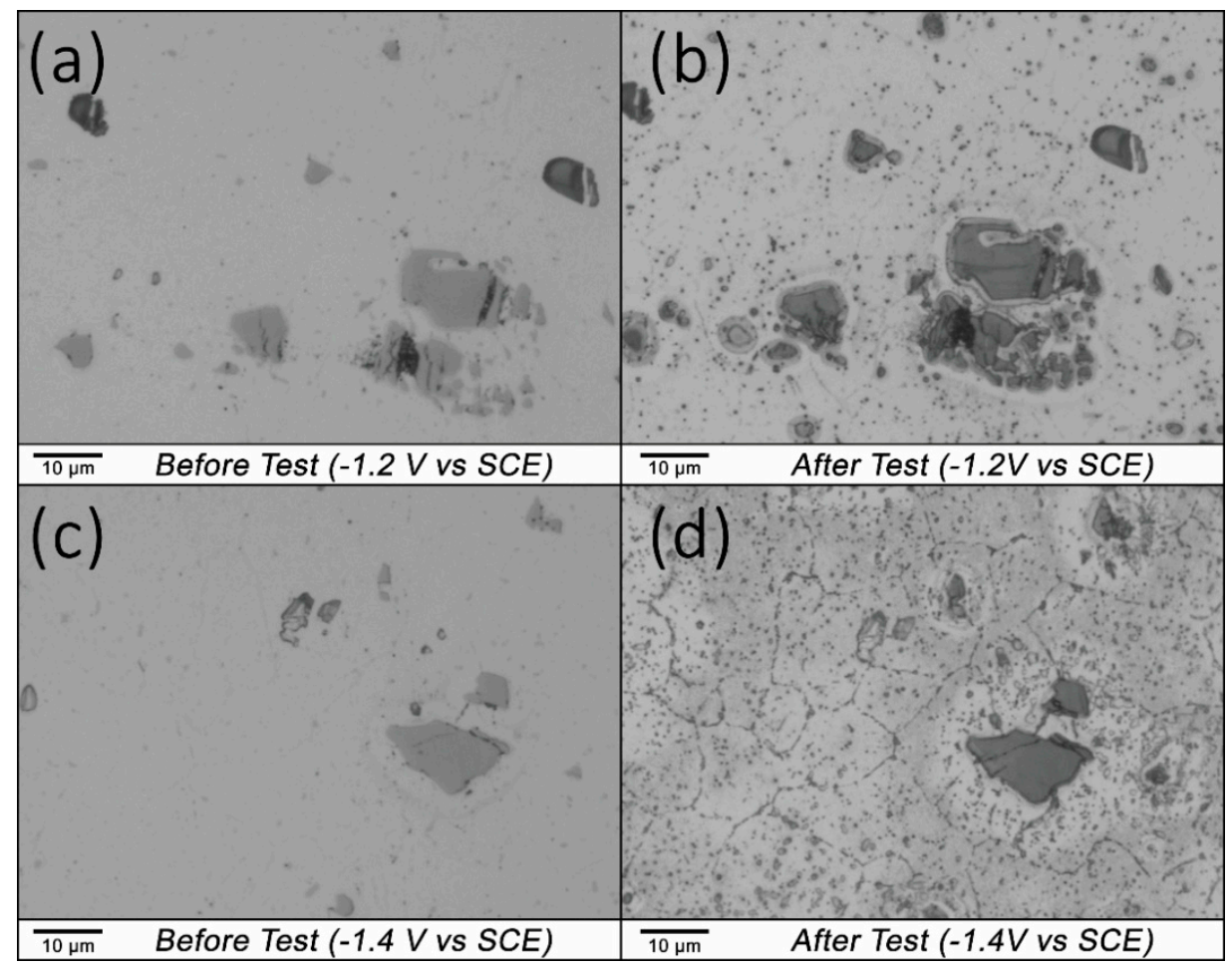

Figure 5. OM analysis of the AA5083 heavily sensitised $\left(175^{\circ} \mathrm{C}\right.$ for three months) microstructure $(\mathbf{a}, \mathbf{c})$ before and $(\mathbf{b}, \mathbf{d})$ after potentiostatic holding at $(\mathbf{a}, \mathbf{b})-1.2 \mathrm{~V}$ vs. SCE and at $(\mathbf{c}, \mathbf{d})-1.4 \mathrm{~V}$ vs. SCE.

Exposure of the (sensitised) AA5083 microstructures to potentials below approximately $-1.35 \mathrm{~V}$ (vs. SCE) in near neutral $\mathrm{NaCl}$ solution can cause the reduction of water (hydrogen evolution), leading to an increase in the localised $\mathrm{pH}$ (up to ca. $\mathrm{pH}$ 10.5) that 
destabilises the passive film [26,27]; Watkins and Davis have previously shown that the surface $\mathrm{pH}$ of aluminum alloys polarized at $-1.4 \mathrm{~V}$ vs. SCE in seawater is in the region of $\mathrm{pH} 10$ to $\mathrm{pH} 10.5$ [28]. Hence, the slight preferential attacks on the $\beta-\mathrm{Al}_{3} \mathrm{Mg}_{2}$ along the grain boundaries at around $-1.4 \mathrm{~V}$ (vs. SCE) during the start of the potentiodynamic full scan is postulated to have contributed to the electrochemical response of the (sensitised) microstructure after breakdown that appears towards the end of the full scan; this provided a discernible trend, illustrated in Figure 4.

\section{Discussion}

\subsection{Possible Factors Contributing to Breakdown Response}

The experimental procedure of starting a full potentiodynamic polarisation scan from $-1.4 \mathrm{~V}$ (vs. SCE) induced a small amount of localised corrosion attacks on the AA5083 microstructure, especially along the grain boundaries (Figure $5 \mathrm{~d}$ ). This can in part explain the dip in cathodic current density observed in the potentiodynamic scans from $-1.4 \mathrm{~V}$ to $-1.35 \mathrm{~V}$ (vs. SCE) in Figure 3 and Figure S2; localised corrosion involves some anodic current, therefore decreasing the net cathodic current density measured at the more negative potentials. The larger the dip, the more anodic current density and thus greater corrosion.

Localised corrosion at $-1.4 \mathrm{~V}$ (vs. SCE) is supported by the work of Gimenez et al. [26], who reported a (purely) experimental E-pH diagram for the AA5086 microstructure immersed in deaerated $1 \mathrm{M} \mathrm{NaCl}$ solution from $\mathrm{pH} 4-9$. It should be noted that the experimental E-pH diagram is in contrast to the traditional Pourbaix diagram (for $\mathrm{Al}-\mathrm{O}-\mathrm{H}$ at room temperature), derived from thermodynamic data of pure aluminium. Gimenez et al. [26] also showed that the microstructure enters the passivity region at potentials above about $-1.35 \mathrm{~V}$ (vs. SCE); this explains why no visible attacks on the grain boundaries are observed in AA5083 (sensitised) microstructures that have been potentiostatically held at $-1.3 \mathrm{~V}$ (vs. SCE) (Figure 5b). However, it has to be mentioned that the (purely) experimental E-pH diagram from Gimenez et al. [26] is not strictly correct. This is because the bulk solution $\mathrm{pH}$ was used as one of the axes, when the involvement of localised $\mathrm{pH}$ changes is crucial to the experimental reactions and observations plotted. The differences in local experimental conditions across the microstructure in part explains for the differences seen between theoretical and experimental values; complex conditions can occur under different experimental setups, while theoretical conditions are usually strictly defined.

Therefore, during the potentiodynamic scans shown in Figures 3 and 4 which started from $-1.4 \mathrm{~V}$ (vs. SCE), the surface of the AA5083 (sensitised) microstructure had firstly undergone slight localised attack on the susceptible grain boundaries; a greater extent of attack is expected for microstructures with a higher DoS (more extensive growth of $\beta-\mathrm{Al}_{3} \mathrm{Mg}_{2}$ ). Lyndon et al. [10] have demonstrated that at all $\mathrm{pH}(2-10)$, the $\beta-\mathrm{Al}_{3} \mathrm{Mg}_{3}$ phase is $200-500 \mathrm{mV}$ more active than the AA5083 matrix, such that the former is capable of supporting high rates of dissolution; the $\beta-\mathrm{Al}_{3} \mathrm{Mg}_{3}$ phase is most likely to have been undergoing the most dissolution when polarized at $-1.4 \mathrm{~V}$ (vs. SCE). Subsequently, upon entering the passive potential region, the surface begins to re-passivate; the region between ca. $-0.9 \mathrm{~V}$ and ca. $-0.7 \mathrm{~V}$ (vs. SCE) shows a clear passive regime. It is possible that the attacked regions were also re-passivated, albeit imperfectly, prior to the breakdown potential; this is similar to the concepts behind the Electrochemical Potentiokinetic Reactivation (EPR) test [29-31] for IGC susceptibility characterisation in austenitic stainless steels.

Trueba and Trasatti [16] recently explored a similar concept-the repassivation response of sensitised and non-sensitised AA5083 microstructures. These authors' investigation [16] focused on the reverse scan (repassivation) when current density reaches $2.5 \mathrm{~mA} \mathrm{~cm}^{-2}$, after a positive direction scan that started from OCP. It was reported that the gradient (in $\mathrm{mV} \mathrm{dec}^{-1}$ ) of the change in current density during repassivation increases as the amount of $\beta-\mathrm{Al}_{3} \mathrm{Mg}_{2}$ in the microstructure increases, due to repassivation being limited by metastable processes driven and sustained by the anodic dissolution of $\beta-\mathrm{Al}_{3} \mathrm{Mg}_{2}$ [16]. These authors [16] also reported that too extensive growth of $\beta-\mathrm{Al}_{3} \mathrm{Mg}_{2}$ appeared to favour 
surface spreading of IGC [12] instead of repassivation, placing a limit on their observable trend.

Similarly, in our work, the initial localised attacks at around $-1.4 \mathrm{~V}$ (vs. SCE) likely revealed the underlying susceptible $\beta-\mathrm{Al}_{3} \mathrm{Mg}_{2}$ in the microstructure. Consequently, during the subsequent passivation stage of the alloy's surface that coincided with potentials positive of the onset of breakdown of (bulk) $\beta-\mathrm{Al}_{3} \mathrm{Mg}_{2}$ itself, reported to be $-0.9 \mathrm{~V}$ (vs. SCE) $[8,10]$, the dissolution of $\beta-\mathrm{Al}_{3} \mathrm{Mg}_{2}$ (in the alloy microstructure) proceeded and limited the passivation of the surrounding regions [16].

Then, as the potentiodynamic scan continues up to the breakdown of the passive film, the imperfectly re-passivated regions in and around the grain boundaries are preferentially attacked. Microstructures that had been initially attacked to a greater extent at $-1.4 \mathrm{~V}$ (vs. SCE) can be expected to exhibit the electrochemical response of a more rapid increase in current density positive of the breakdown potential; this resulted in the discernible trend seen in Figure 4.

\subsection{Proposed Trend of Sensitised AA5083 Microstructure}

While definitive breakdown potentials are difficult to obtain from Figure 4, the electrochemical potentiodynamic polarisation scans in this work have shown that a discernible trend can be obtained from the electrochemical breakdown response, starting from the potential at which current density reaches around $2 \times 10^{-6} \mathrm{~A} \mathrm{~cm}^{-2}$ (Figure 4). A deeper analysis into the differences of the potential at three different points of the curves, when the current density reaches $1 \times 10^{-5}, 1 \times 10^{-4}$, and $1 \times 10^{-3} \mathrm{~A} \mathrm{~cm}^{-2}$ (after breakdown), is illustrated in Figure 6.

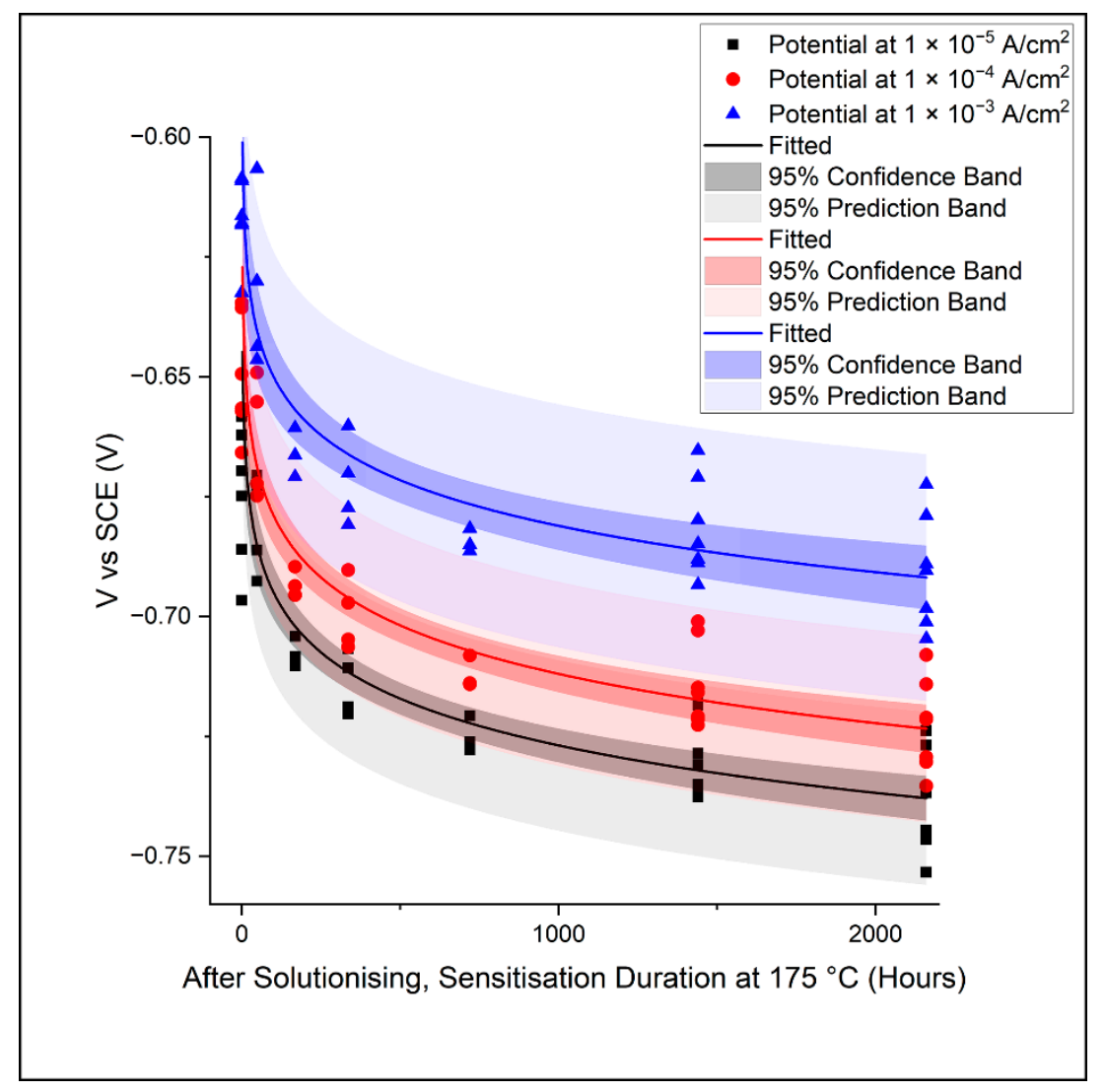

Figure 6. Discernible trend of the potential after breakdown at $1 \times 10^{-5}, 1 \times 10^{-4}$, and $1 \times 10^{-3}$ $\mathrm{A} \mathrm{cm}{ }^{-2}$ current density, plotted against the duration of isothermal sensitisation heat treatment at $175^{\circ} \mathrm{C}$. 
In general, for all three sets of data considered in Figure 6, there is a decrease in the potential at which the set current density is reached with increasing isothermal sensitisation heat treatment duration at $175^{\circ} \mathrm{C}$; this is correlated to the increase in growth of $\beta-\mathrm{Al}_{3} \mathrm{Mg}_{2}$ (both in amount and in size) in the microstructure with increased sensitisation duration. The more extensive the $\beta-\mathrm{Al}_{3} \mathrm{Mg}_{2}$ in the microstructure, the more rapid the increase in current density after breakdown, as was explained in the previous section.

Additionally, the dependence of the (negative) potential shift in Figure 6 is relatively stronger for the first $500 \mathrm{~h}$ of isothermal heat treatment at $175{ }^{\circ} \mathrm{C}$ applied onto the AA5083 microstructure than for longer durations; a negative shift of about $70 \mathrm{mV}$ is predicted for samples exposed to $500 \mathrm{~h}$ of isothermal heat treatment (at $175^{\circ} \mathrm{C}$ ), as compared to only an additional $20 \mathrm{mV}$ negative shift for longer durations up to $2160 \mathrm{~h}$ (Figure 6). The result here is expected and intuitive, and correlates well with the observed (Table 2) and reported [7] saturation of growth of $\beta-\mathrm{Al}_{3} \mathrm{Mg}_{2}$ in the AA5083 microstructure over an extended period of isothermal sensitisation heat treatments (Figure 7).

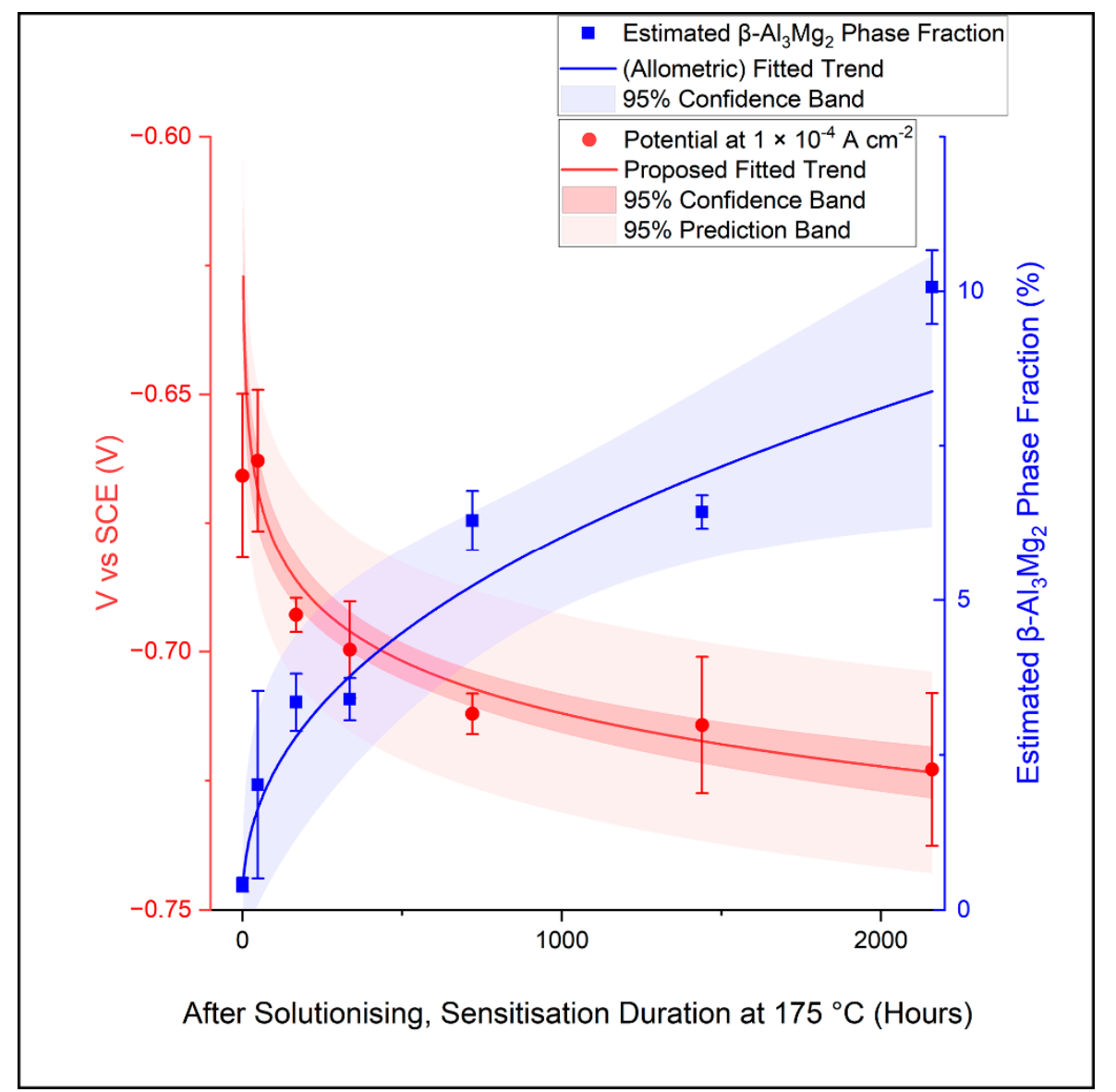

Figure 7. Proposed (fitted) trend curve (in red) derived from the potential data set collated when the current density of the potentiodynamic polarization curves reached $1 \times 10^{-4} \mathrm{~A} \mathrm{~cm}^{-2}$ after breakdown. The estimated fraction of $\beta-\mathrm{Al}_{3} \mathrm{Mg}_{2}$ (and dispersoids) in the microstructures, as indicated in Table 2, is plotted (in blue) for comparison.

Further comparison of the three sets of data in Figure 6 indicates that the set taken at the potential when the current density reached $1 \times 10^{-4} \mathrm{~A} \mathrm{~cm}^{-2}$ after breakdown (Figure 6, red line) provided a marginally wider negative shift $(97 \mathrm{mV})$ over the $2160 \mathrm{~h}$ of isothermal sensitisation heat treatments, including a narrower $95 \%$ confidence and prediction band, as compared to the two other data sets $(91 \& 93 \mathrm{mV})$. Obtaining the potential data set at a lower current density of $1 \times 10^{-5} \mathrm{~A} \mathrm{~cm}^{-2}$ after breakdown (Figure 6, black line) meant that the metastable nature of the breakdown still contributes to the noise in the data set 
(Figure 4). Conversely, acquiring the potential data set at the higher current density of $1 \times$ $10^{-3} \mathrm{~A} \mathrm{~cm}^{-2}$ after breakdown (Figure 6, blue line) involves approaching the transpassive region of the potentiodynamic polarisation curve; this contributes to the loss of resolution of the data set (Figures 4 and 6). Therefore, analysis of the potential data set when the current density reaches $1 \times 10^{-4} \mathrm{~A} \mathrm{~cm}^{-2}$ after breakdown appears to be the better option and will be employed as the "proposed trend" (Figure 7) in further discussions.

\subsection{Final Remarks}

In this work, the experimental procedure managed to condition the AA5083 microstructure surface by introducing a small amount of localised attacks on the susceptible regions, thereby revealing the $\beta-\mathrm{Al}_{3} \mathrm{Mg}_{2}$ phase to behave differently in comparison to the peripheral matrix region during the later stages of the potentiodynamic polarisation scan; this in part solves the issue of the altered surface layer [11] that might have been introduced during the sample preparation grinding and polishing steps. Hence, the proposed (fitted) trend could allow for a correlation of the potential at which the current density reaches a pre-determined value, i.e., $1 \times 10^{-4} \mathrm{~A} \mathrm{~cm}^{-2}$ after breakdown, to the extent of $\beta-\mathrm{Al}_{3} \mathrm{Mg}_{2}$ precipitation in the AA5083 microstructure (Figure 7), and hence the DoS of the microstructure.

However, there are various issues that currently appear to limit the applicability of the proposed (fitted) trend to correlate with actual environmentally-exposed and/or atmospheric-exposed microstructures. Preliminary experiments with the environmentallyexposed and/or atmospheric-exposed samples appear to indicate that the usage of the proposed (fitted) trend in Figure 7 tends to over-estimate the extent of $\beta-\mathrm{Al}_{3} \mathrm{Mg}_{2}$ in the microstructure. Although, it is highly possible that there are other variables that can also influence the electrochemical response of the AA5083 microstructure after breakdown, such as the longer duration of natural aging possibly encouraging a greater $\beta-\mathrm{Al}_{3} \mathrm{Mg}_{2}$ phase continuity formation [4] or the ingress of elements (for example chloride) into the passive film and/or microstructure after an extended exposure to the atmosphere. Both the aforementioned factors would produce a relatively more susceptible AA5083 microstructure.

Overall, the main purpose of this paper is to showcase the ability of an experimental procedure to "prepare" the AA5083 (sensitised) microstructure, providing a possible pathway to analyse the electrochemical response, especially after breakdown; this provides the foundation for the work towards electrochemically quantifying the extent of $\beta-\mathrm{Al}_{3} \mathrm{Mg}_{2}$, degree of sensitisation, and, ultimately, IGC susceptibility of the microstructure of AA5083 components used in industry.

\section{Conclusions}

In this work, the electrochemical response, in particular after passive film breakdown, of the AA5083 microstructure was analysed via a full (positive potential direction) potentiodynamic polarisation scan from $-1.4 \mathrm{~V}$ (vs. SCE) in deaerated $3.5 \mathrm{wt}$ \% $\mathrm{NaCl}$. Considering the results, the following conclusions can be obtained:

- Starting the scan at $-1.4 \mathrm{~V}$ (vs. SCE) results in an increase in surface $\mathrm{pH}$ due to the rapid evolution of hydrogen, which in turn causes active dissolution of part of the AA5083 microstructure, which is likely to be predominately the vulnerable $\beta-\mathrm{Al}_{3} \mathrm{Mg}_{2}$ phase;

- Under the test conditions employed in this study, AA5083 (sensitised) microstructures with a more extensive $\beta-\mathrm{Al}_{3} \mathrm{Mg}_{2}$ growth (from ca. $0.4 \%$ to $8.4 \%$ ) recorded a more rapid increase in the measured current density after passive film breakdown (reaching $1 \times 10^{-4} \mathrm{~A} \mathrm{~cm}^{-2}$ at ca. $-0.63 \mathrm{~V}$ to $-0.72 \mathrm{~V}$ vs. SCE);

- Under the test conditions employed in this study, a fitted correlation was found between the potential at which the current density reaches a pre-determined value, i.e., $1 \times 10^{-4} \mathrm{~A} \mathrm{~cm}^{-2}$ after breakdown, and the extent of $\beta-\mathrm{Al}_{3} \mathrm{Mg}_{2}$ precipitation in the AA5083 microstructure. 
Overall, the observed trend/correlation provides a foundation towards an electrochemical technique to quantify the extent of $\beta-\mathrm{Al}_{3} \mathrm{Mg}_{2}$, degree of sensitisation, and, ultimately, IGC susceptibility of the microstructure of AA5083 components used in industry; optimisation of the experimental variables would be a good approach for future work.

Supplementary Materials: The following are available online at https:/ /www.mdpi.com/article/10

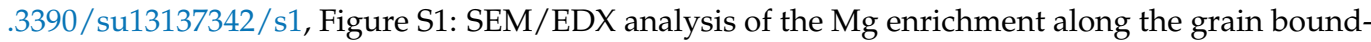
aries, indicating the presence of $\beta-\mathrm{Al}_{3} \mathrm{Mg}_{2}$. Figure S2: Potentiodynamic polarisation curves for the AA5083 (a) as-received microstructure, and the (b-g) sensitised microstructures in deaerated 3.5 wt.\% $\mathrm{NaCl}$ electrolyte. The sensitised microstructures have undergone the additional isothermal heat treatment at $175^{\circ} \mathrm{C}$ for (b) $48 \mathrm{~h}$, (c) $168 \mathrm{~h}$, (d) $336 \mathrm{~h}$, (e) $720 \mathrm{~h}$, (f) $1440 \mathrm{~h}$, and (g) $2160 \mathrm{~h}$. Each curve was done on a separate freshly-polished AA5083 sample. Figure S3: OM analysis of the sensitised AA5083 microstructure after the full potentiodynamic polarisation test (starting at $-1.4 \mathrm{~V}$ vs. SCE) for the isothermally heat-treated (a) $175^{\circ} \mathrm{C}$ for 1 week sample, and the (b) $175^{\circ} \mathrm{C}$ for 1 month sample. Figure S4: OM analysis of the AA5083 heavily sensitised $\left(175^{\circ} \mathrm{C}\right.$ for 3 months) microstructure $(\mathrm{a}, \mathrm{c})$ before and $(\mathrm{b}, \mathrm{d})$ after the potentiostatic hold at $(\mathrm{a}, \mathrm{b})-1.6 \mathrm{~V}$ vs. SCE and at $(\mathrm{c}, \mathrm{d})-2.0 \mathrm{~V}$ vs. SCE.

Author Contributions: Conceptualization, Y.L., S.W. and D.J.B.; methodology, Y.L.; validation, Y.L., S.W. and D.J.B.; formal analysis, Y.L., S.W. and D.J.B.; investigation, Y.L.; writing-original draft preparation, Y.L.; writing - review and editing, S.W. and D.J.B.; supervision, S.W. and D.J.B.; funding acquisition, D.J.B. All authors have read and agreed to the published version of the manuscript.

Funding: This research was funded by the Agency for Science, Technology and Research (A*STAR), under the RIE2020 Advanced Manufacturing and Engineering (AME) Programmatic grant number A1881b0061.

Institutional Review Board Statement: Not applicable.

Informed Consent Statement: Not applicable.

Data Availability Statement: The data presented in this study are available on request from the corresponding author. The data are not publicly available due to forming part of an ongoing study.

Acknowledgments: The authors would like to thank the Structural Metal Alloys Programme of A*STAR (A1881b0061) for financial support. YanHan Liew would like to acknowledge the support of a scholarship from the A*STAR Graduate Academy. The authors would also like to thank JiaWen Peh and YiLing Lai for the experimental support.

Conflicts of Interest: The authors declare no conflict of interest.

\section{References}

1. Vargel, C. 5XXX series alloys. In Corrosion of Aluminium; Elsevier BV: Amsterdam, The Netherlands, 2020 ; pp. 469-484.

2. Yasakau, K.; Zheludkevich, M.; Lamaka, S.V.; Ferreira, M.G. Role of intermetallic phases in localized corrosion of AA5083. Electrochim. Acta 2007, 52, 7651-7659. [CrossRef]

3. Birbilis, N.; Buchheit, R.G. Electrochemical Characteristics of Intermetallic Phases in Aluminum Alloys. J. Electrochem. Soc. 2005, 152, B140-B151. [CrossRef]

4. Lim, M.L.; Kelly, R.; Scully, J. Overview of Intergranular Corrosion Mechanisms, Phenomenological Observations, and Modeling of AA5083. Corrosion 2015, 72, 1818. [CrossRef]

5. Zhang, R.; Knight, S.; Holtz, R.; Goswami, R.; Davies, C.; Birbilis, N. A Survey of Sensitization in 5xxx Series Aluminum Alloys. Corrosion 2016, 72, 144-159. [CrossRef]

6. Gupta, R.; Zhang, R.; Davies, C.; Birbilis, N. Influence of Mg Content on the Sensitization and Corrosion of Al-xMg(-Mn) Alloys. Corrosion 2013, 69, 1081-1087. [CrossRef]

7. Oguocha, I.N.A.; Adigun, O.J.; Yannacopoulos, S. Effect of sensitization heat treatment on properties of Al-Mg alloy AA5083-H116. J. Mater. Sci. 2008, 43, 4208-4214. [CrossRef]

8. Searles, J.L.; Gouma, P.I.; Buchheit, R.G. Stress corrosion cracking of sensitized AA5083 (Al-4.5Mg-1.0Mn). Met. Mater. Trans. A 2001, 32, 2859-2867. [CrossRef]

9. Crane, C.B.; Gangloff, R.P. Stress Corrosion Cracking of Low Temperature Sensitized Al-Mg Alloy. Corrosion 2016, 72, $221-241$.

10. Lyndon, J.; Gupta, R.; Gibson, M.; Birbilis, N. Electrochemical behaviour of the $\beta$-phase intermetallic (Mg2Al3) as a function of $\mathrm{pH}$ as relevant to corrosion of aluminium-magnesium alloys. Corros. Sci. 2013, 70, 290-293. [CrossRef]

11. Seong, J.; Yang, Z.-S.; Scheltens, F.; Frankel, G.S.; Sridhar, N. Influence of the Altered Surface Layer on the Corrosion of AA5083. J. Electrochem. Soc. 2015, 162, C209-C218. [CrossRef] 
12. Jain, S.; Lim, M.; Hudson, J.; Scully, J. Spreading of intergranular corrosion on the surface of sensitized Al-4.4Mg alloys: A general finding. Corros. Sci. 2012, 59, 136-147. [CrossRef]

13. Jain, S.; Hudson, J.; Scully, J. Effects of constituent particles and sensitization on surface spreading of intergranular corrosion on a sensitized AA5083 alloy. Electrochim. Acta 2013, 108, 253-264. [CrossRef]

14. Jones, R.H.; Baer, D.R.; Danielson, M.J.; Vetrano, J.S. Role of Mg in the stress corrosion cracking of an Al-Mg alloy. Met. Mater. Trans. A 2001, 32, 1699-1711. [CrossRef]

15. De De Micheli, S.M. The electrochemical study of pitting corrosion of aluminium in chloride solutions. Corros. Sci. 1978, 18, 605-616. [CrossRef]

16. Trueba, M.; Trasatti, S. The repassivation response from single cycle anodic polarization: The case study of a sensitized Al-Mg alloy. Electrochim. Acta 2018, 259, 492-499. [CrossRef]

17. G01 Committee. Test Method for Determining the Susceptibility to Intergranular Corrosion of 5XXX Series Aluminum Alloys by Mass Loss after Exposure to Nitric Acid (NAMLT Test); ASTM B Stand; ASTM International: West Conshohocken, PA, USA, 2019. [CrossRef]

18. Liew, Y.; Örnek, C.; Pan, J.; Thierry, D.; Wijesinghe, S.; Blackwood, D.J. In-Situ Time-Lapse SKPFM Investigation of Sensitized AA5083 Aluminum Alloy to Understand Localized Corrosion. J. Electrochem. Soc. 2020, 167, 141502. [CrossRef]

19. Yi, G.; Sun, B.; Poplawsky, J.D.; Zhu, Y.; Free, M.L. Investigation of pre-existing particles in Al 5083 alloys. J. Alloys Compd. 2018, 740, 461-469. [CrossRef]

20. Gupta, R.K.; Sukiman, N.L.; Fleming, K.M.; Gibson, M.A.; Birbilis, N. Electrochemical Behavior and Localized Corrosion Associated with Mg2Si Particles in Al and Mg Alloys. ECS Electrochem. Lett. 2012, 1, C1-C3. [CrossRef]

21. Yang, Y.-K.; Allen, T. Direct visualization of $\beta$ phase causing intergranular forms of corrosion in Al-Mg alloys. Mater. Charact. 2013, 80, 76-85. [CrossRef]

22. Zhu, Y.; Sun, K.; Garves, J.; Bland, L.G.; Locke, J.; Allison, J.; Frankel, G. Micro- and nano-scale intermetallic phases in AA2070-T8 and their corrosion behavior. Electrochim. Acta 2019, 319, 634-648. [CrossRef]

23. Zhu, Y.; Frankel, G. Effect of Major Intermetallic Particles on Localized Corrosion of AA2060-T8. Corrosion 2019, 75, 29-41. [CrossRef]

24. Kosari, A.; Zandbergen, H.; Tichelaar, F.; Visser, P.; Taheri, P.; Terryn, H.; Mol, J. In-situ nanoscopic observations of dealloyingdriven local corrosion from surface initiation to in-depth propagation. Corros. Sci. 2020, 177, 108912. [CrossRef]

25. Kosari, A.; Tichelaar, F.; Visser, P.; Zandbergen, H.; Terryn, H.; Mol, J. Dealloying-driven local corrosion by intermetallic constituent particles and dispersoids in aerospace aluminium alloys. Corros. Sci. 2020, 177, 108947. [CrossRef]

26. Gimenez, P.; Rameau, J.J.; Reboul, M.C. Experimental pH Potential Diagram of Aluminum for Sea Water. Corrosion 1981, 37, 673-682. [CrossRef]

27. Vargel, C. The corrosion of aluminium. In Corrosion of Aluminium; Elsevier BV: Amsterdam, The Netherlands, 2020 ; pp. 41-61.

28. Watkins, K.G.; Davie, D.E. Cathodic protection of 6351 aluminium alloy in sea water: Protection potential and surface pH effects. Br. Corros. J. 1987, 22, 157-161. [CrossRef]

29. Číhal, V.; Štefec, R. On the development of the electrochemical potentiokinetic method. Electrochim. Acta 2001, 46, 3867-3877. [CrossRef]

30. ISO 12732:2008 ISO 12732:2008 Corrosion of Metals and Alloys_Electrochemical Potentiokinetic Reactivation Measurement Using the Double Loop Method (Based on Cihal's Method). 2008. Available online: https://shop.bsigroup.com/ProductDetail? pid=000000000030172111 (accessed on 29 June 2021).

31. ASTM G108-94(Reapproved 2015) ASTM G108-94 (Reapproved 2015): Standard Test Method for Electrochemical Reactivation (EPR) for Detecting Sensitization of AISI Type 304 and 304L Stainless Steels 2015. Available online: https://www.astm.org/ Standards/G108.htm (accessed on 29 June 2021). 